\title{
Evidentiality in English Research Articles of Applied Linguistics: From the Perspective of Metadiscourse
}

\author{
Linxiu Yang \\ The Foreign Languages School, Shanxi University, China
}

\begin{abstract}
This paper investigates, from the metadiscourse perspective, the linguistic phenomenon of evidentiality in English Research Articles (RAs) of applied linguistics. Based on a corpus of 100 RAs, the study first presents its own classification of evidentiality and their specific lexicogrammatical realizations. Then, following Hyland's metadiscourse model (2005), it examines in detail how different evidential types and linguistic realizations can function as various metadiscourse devices and what roles they can play in the construction and attainment of persuation. The study has shown the multiple metadiscourse functions of evidentiality. It provides a new perspective to understand evidentiality.
\end{abstract}

Index Terms — evidentiality, metadiscourse, RAs

\section{WHAT Is EVIDENTIALITY}

The linguistic phenomenon of evidentiality exists in almost all the languages and has recently become a hot research issue in linguistics. However, there has been no consensus yet on what evidentiality is and what kind of linguistic category it is. Yet, this is the elementary basis for any evidential study for different definitions lead to different perspective and research focus. Therefore, it is necessary to clarify the understanding of evidentiality in the current study before the analysis.

Generally, the disagreements of what evidentiality is mainly occur in the following two aspects: whether evidentiality is a grammatical category or a semantic one and what is the semantic scope of evidentiality.

First, as to whether evidentiality is a grammatical category or a semantic one, studies have shown that it is language-specific. In about a quarter of the world's languages, every statement is required to specify the type of source on which it is based - for example, whether the speaker sees it, hears it, infers it from indirect evidence, or learns it from someone else. This linguistic category, whose primary meaning is information source, is called 'evidentiality'. In Boas'(1938) words, 'while for us definiteness, number, and time are obligatory aspects, we find in another language location near the speaker or someone else, [and] source of information - whether seen, heard, or inferred - as obligatory aspects'(p.133).

From Boas' words, it can be seen that in some languages, evidentiality is an obligatory category. As to how to express evidentiality, different languages demonstrate different evidential systems. Tariana, an Arawak language spoken in the multilingual area of the Vaupes in northeast Amazonia, has a complex evidential system. In this language, one can not simply say 'Jose played football'. Instead, speakers have to specify whether they see the event happen, hear it, or know about it because somebody else tells them, etc. This is achieved through a set of evidential markers fused with tense. Omitting an evidential in Tariana will result in an ungrammatical and highly unnatural sentence. Look at the following examples.

(a) Juse ifida di-manika-ka.

'Jose has played football (we saw it)'

(b) Juse ifida di-manika-mahka.

'Jose has played football (we heard it)'

(c) Juse ifida di-manika-nihka.

'Jose has played football (we infer it from visual evidence)'

(d) Juse ifida di-manika-sika.

'Jose has played football (we assume this on the basis of what we already know)'

(Adapted from Aikhenvald, 2004:2)

The examples above illustrate that the evidentiality is obligatory in the language of Tariana. To mark the information source, some markers are used, such as $\boldsymbol{k a}$, mahka, nihka and sika, which are termed as evidentials or evidential markers in evidential studies. These instances show that in Tariana evidentiality is a grammatical category and it is expressed through affixes or clitics. However, this is only one of the understandings concerning evidentiality and evidentials. If evidentiality is defined from the formal perspective, it seems that evidentiality only occurs in some languages, but not universal. For example, in the languages of English, Chinese, German and so on, there are no 
grammaticalised evidential systems. In these languages, there are no affixes or clitics to express evidentiality. Thus, concerning evidentiality, there exist different research orientations. While some linguists still show great enthusiasm for describing the grammatical evidential systems of some languages, more researchers agree that evidentiality is not a grammatical form, but a semantic category. It is agreed that the semantics of evidential is universal and exist in almost all the languages in the world. The differences exist in whether it is obligatory or optional and how the semantics is construed in grammatical, lexical or whatever forms. For example, Japanese presents a quite complex system of evidential coding. It has both grammaticalised and non-grammaticalised evidentials (Mushin, 2001). Unlike Tariana and Japanese, the evidential category in English is not grammaticalised (Lazard, 2001). Yet, English has a rich repertoire of evidential devices (Chafe, 1986). It has a broad range of devices such as verbs, adverbs, adjectives, nouns and so on. According to Chafe (1986), the difference between some Indian languages and English in evidentiality is not a matter of evidential vs. no evidentials. It is partly a question of how evidentiality is expressed: is it by suffixes, adverbs and what?

Studies have also shown that some linguists still stick to the grammaticalised evidentials and exclude other realization forms of evidentiality. However, more researchers tend to take evidentiality as a semantic one and study various forms in different languages. In English, if evidentiality is taken as a grammatical category, just as in some Indian languages, it appears unnecessary to study evidentiality, for there seems to be no grammaticalised evidentials. In fact, many researchers have been studying evidentiality in English (e.g. Chafe, 1986; Palmer, 1990, 2001; Mushin, 2000, 2001; Halliday \& Matthiessen, 2004; Hu, 1994; Fang, 2005; Tang, 2007; Yang, 2009, 2010), which shows that the notion of evidentiality as a semantic one has been broadly accepted. This study also takes evidentiality as a semantic notion.

Secod, there has been no common understanding of the semantic scope of evidentiality. It is claimed (Aikhenvald, 2004) that evidentiality is an obligatory grammatical category in the language of Tariana whose primary meaning is to indicate the source of information. This view is considered as the narrower understanding of evidentiality in evidential studies. Bussemann (1996, one of the linguists who hold the narrow view on evidentiality, defines evidentiality as "the structural dimension of grammar that codifies the source of information transmitted by a speaker with the aid of various types of constructions" (p. 157). Aikhenvald (2003) also overtly declares the narrow view of evidentiality. She defines the term 'evidentiality' in its strict grammatical sense. She holds that the gratuitous extension of evidentiality to cover every way of expressing uncertainty, probability and one's attitude to the information is one of the current misconceptions concerning evidentiality. She thinks that this extension will be unhelpful and quite uninformative and that this approach obscures the status of evidentiality distinct from modality, mood and tense. Those who hold the narrow definition of evidentiality mainly put their focuses on some highly-inflectional languages and concentrate on the detailed descriptions of the grammatical evidential systems.

However, this is only one side of the coin. There is another understanding which holds that with the indication of information source as the core meaning, evidentiality may also be related to the degree of the speaker's certainty of the information. Compared with the previous one, this is a broad view of evidentiality. First, it does not confine evidentiality to a grammatical one. Instead, it treats evidentiality as a semantic notion and whatever forms of evidentials are within the scope of research. Second, evidentiality, in addition to indicating the information source, may acquire other meanings - of reliability, probability, possibility, etc. Third, the semantics of evidentiality is universal, and is expressed in different languages. Some languages have grammaticalised systems to indicate evidentiality, but others not. In some languages, evidentiality is obligatory, but in others not. Chafe (1986) is the leading figure who defines evidentiality in its broadest sense. He defines evidentiality as 'attitude toward information'. Under the broader definitions, both grammatical evidentials and lexical ones are taken into considerations. Therefore, evidential studies are not only confined to those languages with grammatical evidential systems, but also extended to almost all the languages in the world.

In spite of different opinions toward evidentiality stated above, in this paper, I take evidentiality as a semantic notion to indicate the information source and at the same time the speaker's degree of commitment to the factual status of the information. It can have various lexicogrammatical realizations, such as grammatical or lexical ones.

\section{Why FROM MetadisCourse PersPective?}

Since the first mention of evidentiality by Franz Boas (1938), many researchers have devoted much to this linguistic phenomenon from various perspectives including typological, cognitive linguistics, pragmatics, systemic functional linguistics and so on (Aikhenvald, 2003, 2004; Chafe \& Nichols, 1986; Lazard, 2001; Martin-Arrese, 2004; Mushin, 2000, 2001, to just name a few). In China, some scholars also study evidentiality from various perspectives (Hu, 1994, 1995; Niu, 2005; Zhu, 2006; Fang, 2005; 2006, 2008; Tang, 2007).

In spite of the recent surge for evidential studies and the achievements made in previous researches, the study is still in its infancy. There are many aspects to be explored. Generally speaking, the previous studies have the following characteristics. First, some researchers still put emphasis on grammatical descriptions of the evidential systems in some languages. Second, the researches seem to be confined to the lexis and clausal level, and evidential studies at discourse and genre level are much fewer than enough. In addition, few systematic researches on evidentiality in academic discourse have been conducted. Third, few studies have touched the interpersonal functions of evidentiality, especially from metadiscourse perspective. 
On considering the limitations of the previous studies on evidentiality, I have found the necessity and urgency of evidential studies at the genre level and from the metadiscourse perspective. Therefore, this paper will fill this gap by focusing on the interpersonal functions of evidentiality, from the metadiscourse perspective, in English Research Articles of applied linguistics.

\section{THEORETICAL CONSIDERATION}

This study takes metadiscourse perspective to examine evidentiality. Metadiscourse, as is defined by Williams (1981), refers to "discourse about discourse, which is irrelevant to the subject matter" (p. 211-212). Crismore (1983) takes a functional approach to metadiscourse, defining it as "the directives given to the readers so they will understand what is said and meant in the primary discourse and know how to take the author" (p.2). He argues that when metadiscourse is used appropriately, the non-content aspect of the text (i.e. metadiscourse) can serve to guide and direct a reader through a text by helping him to understand the text and the author's perspective. Vande Kopple (1985) takes metadiscourse as the discourse about the primary propositional information of the text. It has the functions to guide the readers to organize, classify, reiterate, evaluate and reflected on the information conveyed by the text.

In response to two categorizations of metadiscourse given by Crismore and Vande Kopple, Hyland (2005) holds that there exist ambiguity and uncertainty about what features to be included in the analysis and how to categorize these. He (2005) presents a clear definition of metadiscourse.

Metadiscourse is the cover term for the self-reflective expressions used to negotiate interactional meanings in a text, assisting the writer (or speaker) to express a viewpoint and engage with readers as members of particular community. (p. 37)

Based on a functional approach which regards metadiscourse as the ways the writer refers to the text, the writer or the reader, Hyland builds an interpersonal model of metadiscourse. He regards metadiscourse as a means of conceptualizing the interpersonal relationship. No matter how the metadiscourse is categorized, it is interpersonal by nature. In Hyland's model, metadiscourse consists of two dimensions of interactions (Hyland, 2005).

1. The interactive dimension. This concerns the writer's awareness of a participating audience and the ways he or she seeks to accommodate its probable knowledge, interests, rhetorical expectations and processing abilities. The writer's purpose here is to shape and constrain a text to meet the needs of particular readers, setting out arguments so that they will recover the writer's preferred interpretations and goals.

2. The interactional dimension. This concerns the ways the writer conducts an interaction by intruding and commenting on their message. The writer's goal here is to make his or her views explicit and to involve readers by allowing them to respond to the unfolding text. This is the writer's expressions of a textual 'voice', or community-recognized personality, and includes the ways he or she conveys judgements and overtly aligns him- or herself with readers. Metadiscourse here is essentially evaluative and engaging, expressing solidarity, anticipating objections and responding to an imagined dialogue with others. It reveals the extent to which the writer works to construct the text with readers.

Based on the two dimensions, the categorizations of metadiscourse can be modeled as the following table shows.

TABLE 1

HYLAND'S CATEGORIZATION OF METADISCOURSE

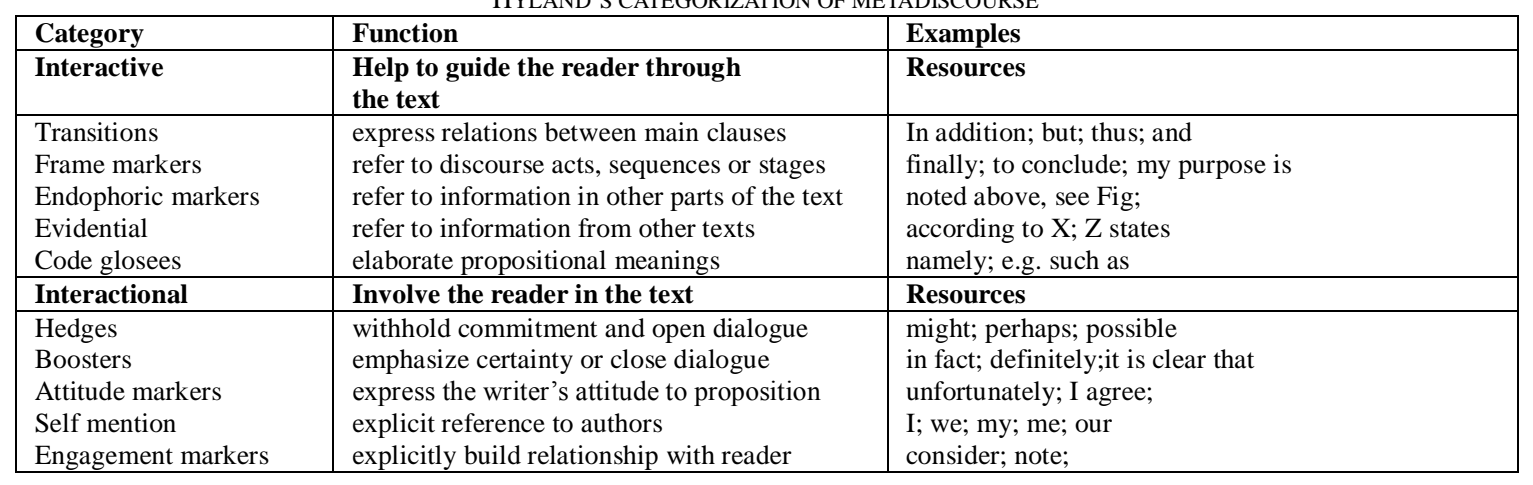

From the above model, we can see that in the category of interactive metadiscourse, "evidential", but it differs from "evidentiality" in this study. In my study, the semantics of evidentiality is more than "evidential" in Hyland's metadiscourse model. In the following analysis, I will classify evidentiality into different types (see Section 5.1). It is supposed that different types of evidentiality can function as metadiscourse devices, such as the inferring evidentials, such as may, must, might, and possibly, can function as hedges or boosters in this model.

Based on Hyland's model, I extend evidentiality into metadiscourse model to check the multifunctionality of evidentials in RAs of Applied Linguistics. It is hope to prove that by choosing the appropriate evidentials, the RA writer can interact with the reader and also make the propositional content more coherent, intelligible and persuasive to the reader. 


\section{DATA AND MEthodology}

The corpus consists of 100 RAs in Applied Linguistics amounting to about 700,000 words. The articles are downloaded from the Internet (www.elsevier.com). The journals selected for this study are: Journal of English for Academic Purposes (2004-2008), Journal of English for Specific Purposes (2004-2008), and Journal of Pragmatics (2004-2008). The data of RAs are confined to the same period because of the fact that genres are on the one hand quite stable in a certain period of time. On the other hand, they are also in a state of constant evolution, as Fairclough (1992) notes, "a genre implies not only a particular text type, but also particular processes of producing, distributing and consuming text.... Changes in social practice are both manifested on the plane of language in changes in the system of genre, and in part brought about by such changes". The genre of RAs also may change over time. Therefore, in order to examine the linguistic features of RAs, the study chooses RAs published during the same time for the validity of the research results.

The data-coding of this research is done manually at the preliminary stage to identify and count all the potential lexical and discourse-based items that indicate different evidential types. The material for data-coding includes the body of the articles, i.e. the complete text of the articles, excluding abstracts, notes, linguistic examples, tables, and figures. Then, Microsoft Office Excel is adopted to deal with the data and draw the figures accordingly. In addition, in order to take the context of evidentials into consideration to find the concordance patterns, a concordance software is also adopted. The statistical results are the basis for later illustration of evidentiality as a discourse strategy to fulfill the function of metadiscourse. The frequency of occurrence of each group of items is calculated in permillage.

\section{FINDINGS AND DisCUSSIONS}

\section{A. Classification of Evidential in the Current Study}

Based on the previous classifications of evidentiality and considering the unique generic characteristics of RAs, this research takes the broader view of evidentiality proposed by Chafe(1986) and the same time it draws on Willett's and Tang's classifications(2007). Although we admit that evidentiality can reveal attitude toward knowledge in addition to indicating information source, this attitude is not as broad as Chafe's. Evidentiality only concerns the speaker/writer's attitude toward the factual status of knowledge. For example, in the proposition "It is important that the corpus ...", "it is important" indicates the attitude toward the proposition "the corpus ...", but this kind of attitude is beyond the scope of the evidential analysis, for it is not about the factual status of the proposition.

The preliminary sample survey shows that four evidential types frequently occur in the genre of RAs: sensory evidentials, reporting evidentials (further divided into other-reporting and self-reporting evidentials), inferring evidentials, and belief evidentials. The classification is shown in Figure 1.

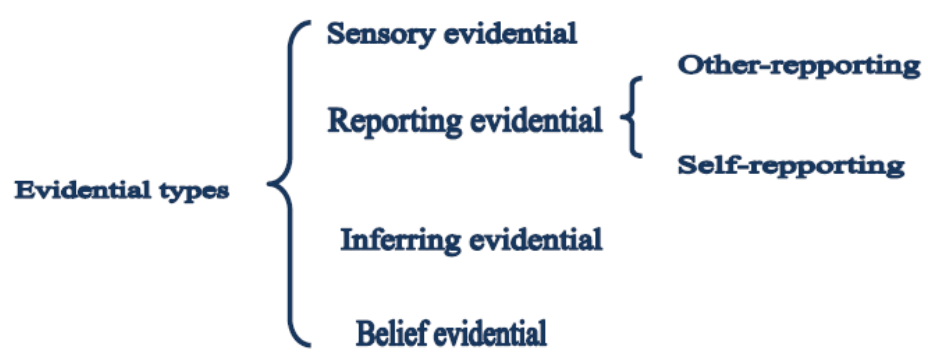

Figure 1 Classification of evidentiality in the current study

\section{B. Lexicogrammatical Realizations of Evidential Types in RAs}

Based on the corpus, we conclude the lexicogrammatical patterns of evidential types in RAs in Table 2 for a clearer picture. 
TABLE 2

LEXICOGRAMMATICAL PATTERNS OF EVIDENTIAL TYPES IN RAS

\begin{tabular}{|c|c|c|c|}
\hline $\begin{array}{l}\text { Evidential } \\
\text { types }\end{array}$ & \multicolumn{2}{|c|}{ Typical Realizations } & Examples \\
\hline \multirow{3}{*}{$\begin{array}{l}\text { Sensory } \\
\text { evidential type }\end{array}$} & \multicolumn{2}{|c|}{ first-person pronoun plus see verbs or passive forms of see } & I/we see; be seen \\
\hline & \multicolumn{2}{|l|}{ it is/can be seen } & It is/can be seen that \\
\hline & \multicolumn{2}{|l|}{ as (be) seen } & as seen above \\
\hline \multirow{4}{*}{$\begin{array}{l}\text { Belief } \\
\text { evidential type }\end{array}$} & \multirow[t]{2}{*}{ subjective } & I/we+mental state verb & I think; I believe; I/we suggest \\
\hline & & Adjunct & In my/our view, \\
\hline & \multirow[t]{2}{*}{ objective } & it (modal verb)+mental state verbed & $\begin{array}{l}\text { It can be suggested; it may be } \\
\text { tentatively argued }\end{array}$ \\
\hline & & Adjunct & arguably; admittedly \\
\hline \multirow{6}{*}{$\begin{array}{l}\text { Reporting } \\
\text { evidential type }\end{array}$} & \multicolumn{2}{|c|}{ (author+year) or (website+year) } & (Hunston, 2000) \\
\hline & \multirow[t]{3}{*}{ Verbal realization } & verb that structure, be verbed structure, & $\mathrm{X}$ argue, maintain, found, ... that \\
\hline & & it is ved structure & It is argued, it has been revealed \\
\hline & & as structure. & as indicated by... \\
\hline & \multirow[t]{2}{*}{$\begin{array}{l}\text { Non-verbal } \\
\text { realization }\end{array}$} & noun that & $\begin{array}{l}\text { fact, observation, agreement, finding, } \\
\text { view, claim, }\end{array}$ \\
\hline & & Adjunct & according to $\mathrm{X}$, in X's data, in X's view \\
\hline \multirow{4}{*}{$\begin{array}{l}\text { Inferring } \\
\text { evidential type }\end{array}$} & \multicolumn{2}{|l|}{ Modal verbs } & can; may;could; might; must; \\
\hline & \multicolumn{2}{|l|}{ Relational process } & Seem to/that; appear to/that \\
\hline & \multicolumn{2}{|l|}{ Modal adjunct } & $\begin{array}{l}\text { clearly, probably, evidently, possibly, } \\
\text { certainly, obviously, }\end{array}$ \\
\hline & \multicolumn{2}{|c|}{ impersonal it structure } & $\begin{array}{l}\text { it's possible that, it's certain that, it's } \\
\text { clear that, it's evident that }\end{array}$ \\
\hline
\end{tabular}

\section{Evidentiality as Metadiscourse}

\section{Evidentiality as interactive metadiscourse}

According to Hyland's model, interactive metadiscourse aims to organize propositional information in the ways that a projected target audience is likely to find coherent and convincing. Clearly, they are not simply text-organizing. They are a consequence of the writer's assessment of the reader's assumed comprehension capacities, understandings of the related texts, and need for interpretive guidance, as well as the relationship between the writer and the reader. Under this heading, several categories are included, such as transitions (in addition to, but, thus, and) to express the relations between the main clauses, frame markers (finally, to conclude, my purpose is) to refer to the discourse acts, sequences, or stages, endographic markers(noted above, see Fig) to refer to the information in other parts of the text, evidentials (according to $X, X$ states) to refer to the information from other texts and also code glosses (namely, e.g., such as) to elaborate the propositional meanings. All these metadiscourse markers help to create a reader-friendly text for they can guide the reader through the text and make it more possible for the information to be interpreted in the way preferred by the writer.

As for the metadiscourse functions of evidentiality, it is found that in RAs, different evidentials can function as different types of interactive metadiscourse with the same purpose of making the writing more coherent and more convincing. The following are the specific analyses.

First, other-reporting evidentials can function as what are referred to as evidentials (they are not in the broad sense of evidentialitiy in the current research) in the metadiscourse model by Hyland (2005). Evidentials in the model are used in a narrow sense and refered to 'metalinguistic representations of an idea from another source' (Thomas \& Hawes, 1994). They can function as a guide to the reader's interpretation and establish an authorial command of the subject. They may involve hearsay or attribution to a reliable source. In academic writing, they often refer to a community-based literature and provide important support for argument.

Other-reporting evidentials are usually studied as "citations" in RAs. This explicit reference to prior literature is a substantial indication of a text's dependence on contextual knowledge and thus a vital piece in the collaborative construction of new knowledge between writers and readers. The embedding of arguments in networks of references not only suggests a cumulative and linear progression, but reminds us that statements are invariably a response to previous statements. Fairclough (1992), extending Bakhtin, refers to these intertextual relations as 'manifest intertextuality', which he distinguishes form 'constitutive intertextuality':

In manifest intertextuality, other parts are explicitly present in the text under analysis; they are 'manifestly' marked or cued by features on the surface of the text such as quotation marks....The constitutive intertextuality of a text, however, is the configuration of discourse conventions that go into its production. (p.104)

Other-reporting evidentials also show the interaction between the writer, the cited author and the cited information. Through the evaluative functions in other-reporting evidential type discussed above, the writer shows his relative stances in relation to the cited authors and the cited information, which will guide the reader to interpret the propositions in the way anticipated by the writer so that the persuasive purpose will be obtained.

Second, self-reporting evidentials in RAs can function as endophoric markers. Endophoric markers are the expressions which refer to other parts of the text (as noted above, as discussed in Chapter 2). They make additional ideational material salient and therefore available to the reader in aiding the recovery of the writer's meanings, often 
facilitating comprehension and supporting argument by referring to earlier materials or anticipating something yet to come. By guiding the reader through the discourse, these markers help to steer the reader to a preferred interpretation or reacting to the discourse. As discussed above, self-reporting evidentials can indicate that the information is from the writer himself, such as the writer(s), the article, our research, our data, our analysis, our tables and figures, our examples and so on. At the same time they can steer the reader's thinking and influence his/her interpretation of the given information.

(1) As noted earlier, the ability to cite appropriately is of key importance in academic writing, but presents considerable difficulty for the novice writer.

(2) This paper will focus specifically on the use of retrospective labels in the construction of stance, as illustrated in (1) below.

(3) Moreover, as noted above, these labels are interactive; their use affects the reader's perception of the propositions and so enables the reader to perceive the organization and meaning that the writer intends.

In the examples above, the evidentials as noted earlier, as illustrated in (1) below, as noted above function as 'endophoric markers'. These markers 'play an important role in making additional ideational material salient and therefore available to the reader in aiding the recovery to the writer's argumentative intentions' (Hyland, 1998). Endophoric markers are important in the process of persuation in academic writing because the reader always has the possibilities of reinterpreting the propositional materials and even rejecting the writer's viewpoints. In order for the reader to recover the writer's intentions, the writer has to anticipate and respond to the possible negation of his claims.

\section{Evidentiality as interactional metadiscourse}

Different from interactive metadiscourse, interactional metadiscourse involves readers and opens the opportunities for them to contribute to the discourse by alerting them to the writer's perspective towards both the propositional information and readers themselves. They can control the level of personality in a text as the writer acknowledges and connects to others, pulling readers along with their argument, focusing their attention, acknowledging their uncertainties and guiding them to interpretations. Interpersonal metediscourse resources are the means by which the writer expresses his views and engages with the socially determined positions of others. They therefore act to anticipate, acknowledge, challenge or suppress alternative, potentially divergent positions and expand or restrict opportunities for such views (White, 2003). Under this heading, several categories are included, such as hedges (might, possible, perhaps) to withhold commitment and open dialogue, boosters (in fact, definitely, it is clear that...) to emphasize the certainty or close the dialogue, attitude markers (unfortunately, I think, I agree) to express the writer's attitude to proposition, self mention ( $I$, we, my, our) to explicit reference to the author and engagement markers (consider, note) to explicitly build relationship with the reader. These metadiscourse markers are the means to involve the reader in the text and make the reader actively involved in the text construction. Just as evidentiality can function as interactive metadiscourse, the following will show how evidentiality can function as interactional metadiscourse.

First, evidentials functions as hedges. Hedges are the devices indicating the writer's decision to recognize alternative voices and viewpoints and therefore withhold complete commitment toward a proposition. Hedges emphasize the subjectivity of a position by allowing the information to be presented as an opinion rather than a fact and therefore open that position to negotiation. Hedges imply that a statement is based on the writer's plausible reasoning rather than certain knowledge, indicating low degree of confidence. Some types of evidentials can function as hedges to show the writer's partial commitment to the validity of propositions.

Inferring evidentials are the primary group to function as hedges. Inferring evidentials, such as might, may, perhaps, possible, probably, and so on, function as hedges in that they indicate low commitment to the validity to propositions. They open a space for alternative viewpoints and negotiation with the reader. For example:

(4) It is possible that thesis writers tend to deal with the literature by discussing individual papers at some length, rather than by subsuming a number of papers under a single comment.

(5) Thus, it may be more appropriate for a thesis writer to use a verb when dealing with aspects of the literature where there is a conflict or uncertainty.

In Examples (4) and (5), by using the two evidentials it is possible that and may as hedges, the writers withhold their full commitment to the propositions and suggest what they present is just one of the several possibilities. These evidentials, on the one hand, reveal the uncertainty of the truth. On the other hand, it is a strategy that the writer uses to avoid taking full responsibility for the factual status of the propositions. By using them, the writer expects the possible negation, criticism or later confirmation from other researchers. By revealing the uncertainty of truth, the writer adopts these evidentials to function as hedges to distance himself from the propositions and opens the dialogic space for the propositions.

Some self-reporting verbs can also function as hedges. Self-reporting evidentials are mainly adopted in Findings and Discussion and Conclusion parts to report what the writer has found and what the findings can indicate. In these two parts, the writer often chooses more tentative reporting verbs rather than the assertive and factive ones. Assertive and factive verbs will give the impression of imposing and close down the negotiation space between the writer and the reader. Therefore, in order to be more modest and more reader-friendly, when the writer presents his findings, he tends to choose some tentative reporting verbs. In the corpus, it is found that the most frequently used tentative reporting verbs is suggest with the occurrence of 21 out of the total self-reporting verbs. 
(6) These results suggests that the majority of researcher in a second language acquisition research tend to employ the move the structure M1-M2-Ms, which is to say they first establish the territory in M1, then establish the niche in M2, and end their RA introductions by occupying the niche in M3.

(7) Our study shows that problems with perception have a significant and system impact on the very common, familiar settings of many conversations in noisy rooms.

The examples above adopt the self-reporting evidentials suggest and show to show what the writer has found in the research, but different verbs are used. The verb suggest here functions as a hedging device, as it allows the writer to withhold the whole commitment to the propositions so that the writer will take less modal responsibility. In contrast, the verb show is different in functions, as it can indicate the writer's higher degree of commitment and higher degree of modal responsibility, which is categorized as boosters, and will be discussed in the following part.

Belief evidentials can also function as hedges. Belief evidentials refer to the writer's overt opinion of a proposition, such as I believe, I argue, I think, in my view, to my knowledge, and so on. They provide a way to confine the commitment to the proposition to the writer him/herself and allow for alternative viewpoints.

(8) A further reason stems, I think, from the nature of the thesis itself.

(9) I suggest that the ability to handle nouns used as retrospective labels is important for thesis writers.

The belief evidentials like I think and I suggest in the two examples above indicate the subjective intrusion of the writers into the propositions. They confine the views to their own, which shows the writers' full responsibility for what they think or believe. By using these evidentials as hedges, the writer admits the possible alternative views from others. Therefore, it can be a politeness strategy for face-saving for both the writer and the reader. However these belief evidentials are the most explicit and subjective way for the writer to be involved in the text. In order to keep the objectivity of RAs, these cases are not very common in our data.

In conclusion, by using evidentials as hedges, the writer makes his claims less assertive and imposing. He makes a dialogue with the reader, expects the possible objections from others, and expresses his less certainty of the propositions. Although hedges show the writer's tentativeness in claim-making, his credibility is consolidated because of the relativity of truth in the world.

Second, evidentials functions as boosters. Boosters, in contrast to hedges, are words such as clearly, obviously, and demonstrate, which allow the writer to close down alternatives, head off conflicting views and express his certainty of his claims. They suggest that the writer recognizes the potentially diverse positions but has chosen to narrow this diversity rather than enlarge it, confronting alternatives with a single, confident voice. By adopting boosters, the writer is confident and shows his certainty of the validity of the proposition.

The above has mentioned that inferring evidentials can function as hedges, but contrary to the ones as hedges, some inferring evidentials such as evident, clear, likely, must, can, shall and so on can also function as boosters and denote the high reliability and high modal value. Such inferring evidentials suggest that the writer has quite reliable evidences to show strong commitment to the validity of the propositions. For example:

(10) As is evident, the difficulties understanding what was needed in this advisor/advisee relationship went both ways.

(11) It is clear from this example that much work remains to be done to shed further light on the role of personal voice or stance and the means by which it is realized.

By using the two evidentials as is evident and it is clear, the writers indicate that they have strong evidence to support what they present. They make strong claims and have high degrees of commitment to them. These strong claims show the authority and assertiveness on the part of the writer, which is also a very important persuasive strategy because the reader will not believe the writer who is all the time conservative and tentative.

Besides inferring evidentials, some self-reporting evidentials can also function as boosters such as demonstrate, argue and show. In contrast to hedges, they do not show the writer's modesty and hesitation to present his findings and study. Instead, they show confidence and eagerness to present what they have found. However, it should be noted that there is a balance between hedges and boosters. To present his study and findings, the writer can not use boosters all the time to show his confidence. However, too many boosters will give an impression of imposing and no respect for the reader. The reader may feel too imposed to accept what the writer expresses. Thus, keeping a dynamic balance between boosters and hedges is quite important.

As mentioned above, self-reporting evidentials can function as both boosters and hedges. However, the study has found an unbalanced use of self-reporting verbs as boosters and as hedges, as shown in Figure 2. 


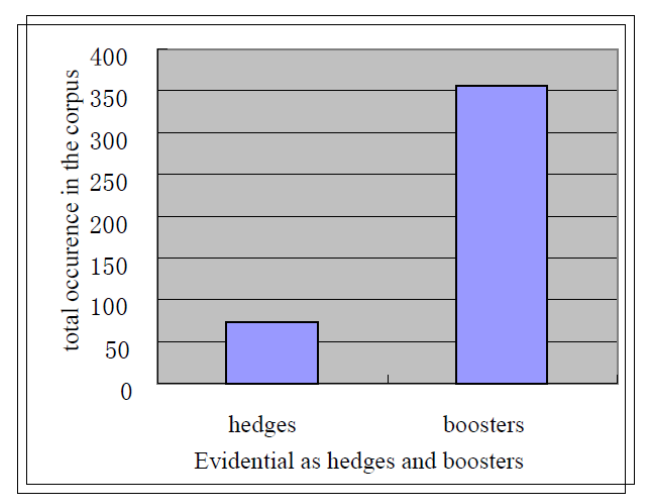

Figure 2 Comparison of self-reporting evidentials as boosters and hedges

Figure 2 clearly shows the unbalanced use of self-reporting evidentials as hedges ( $\mathrm{f}=74)$ and boosters ( $\mathrm{f}=358$ ). However, the result does not show that when presenting claims, the writer uses more boosters than hedges. It can only tell us that in making strong claims and in showing high degrees of commitment, the writer tends to choose self-reporting evidentials rather than other means, such as modal verbs. They indicate that for high degrees of commitment, the writer is more likely to choose verbal (objective) forms rather than the more subjective forms such as modal verbs, or belief evidentials. The subjective way is preferred when presenting the lower degree of commitment.

Some information sources can also function as boosters when the assertive reporting verb collocates with the information source such as the data, the example, the analysis, the table and the scholars and their related findings. The reliability of information will be improved, for these sources are the ones that the reader tends to rely on. The choice of a reliable information source is also a persuasive strategy to make strong and assertive claims more convincing and reliable for readers to accept. In the use of other-reporting evidential type, the writer generally chooses the scholars and researchers concerning the research to be the information sources, which the reader finds more reliable. The study also finds that the sources in self-reporting type reveal the writer's reliance on the multi-modality by frequent reference to tables, figures, examples and so on. With concrete sources which the reader can refer to directly, he will be more likely to be convinced of the claims.

Third, evidentials function as self-mention. Self-mention refers to explicit authorial presence in the text by adopting first person pronouns and possessive adjectives (I, me, mine, exclusive we, our, ours). All the writings carry the information about the writer, but the convention of personal projection through first-person pronouns is perhaps the most powerful means of self-representation (Ivanic \& Weldon, 1998). The writer can not avoid projecting his/her impression and how he stands in relation to his argument, his community and the reader. The presence or absence of explicit authorial reference is generally a conscious choice by the writer to adopt a particular stance and a contextually situated authorial identity. In evidentiality, there are quite a number of self-mention cases, which mainly occur in self-reporting and belief evidentials.

Self-reporting evidentials clearly indicate that the information source is the writer or whatever related to the study. For example:

(12) In this cases $\boldsymbol{w} \boldsymbol{e}$ found, this included external sounds that penetrated from outside the building or from adjacent rooms, mechanical and other background....

(13) Our study of conversation in noisy settings suggests that there are also identifiable patterns in the ways that noice and impaired language perception during conversation affect grammatical and discourse....

(14) Our data from both children and adults indicates that noise significantly alters the pragmatics of conversational discourses.

The information sources we, our study, and our data here function as self-mention metadiscourse markers. They clearly refer to the writer, and his related researches. Therefore, this is a strategic device to promote the writer and his researches. Based on our data survey, the semantic and discourse functions of self-mention of vidential are summarized as follows:

i. The writer of a single-authored single refers to himself/herself as we rather than I;

ii. Exclusive we refers to the writers themselves to explain what they have done in research and reveals how they position themselves.

iii. Inclusive we referring to both the writer and the reader serves the discourse function of assuming shared knowledge, goals and beliefs. By doing so the distance between the writer and the reader is shortened and thereby the solidarity of the writer with the community is strengthened.

Belief evidentials are also a primary means for self-mention and they are the most explicit way to present the writer's stance to or viewpoint of the information.

In our data, the typical rhetorical functions of evidentials as self-mentions are presented as follows.

i Evidentials function as the claim-maker to make a claim or statement, or elaborate an argument, as shown in (128) and (129). 
(15) The general findings from our study suggest that metadiscourse is an important feature of professional rhetorical writing in languages other than English...

(16) In the example above, we understand that all members to the field know that uniformity along the length of the superconducting wire is one of the key factors...

ii Evidentials function as the finding announcer to show the results or findings. For example:

(17) our analysis indicates that practioners undertaking research degrees and the academics assessing their texts may have divergent understanding about what counts as legitimate knowledge types, knowers, evidence, intertextual practices, and argumentation.

(18) First of all, consistent with O'zbek's findings, we found that one of the functions of $s$, ey was to index the speaker's planning at a certain points in the discourse by filling a pause in the flow of speech.

In (17) and (18), the writers choose self-reporting evidentials to announce what they have found in their researches. With the self-mention forms "our analysis" and "we" as the information source, the writer and his researches are promoted.

iii Evidentials function as the opinion holder. For example:

(19) Thus taking a case study approach here has made it possible, we think, to begin to identify and exemplify key writing challenges that...

(20) These statements, in our view, reflected the reviewer's belief that the writer was a relative novice rather than an experienced authority.

In Examples (19) and (20), the two belief evidentials we think and in our view are adopted to show that the information is totally from the writers' own points of view. In so doing, the writers are totally responsible for the truth value of the statements, allowing alternative opinions from others and thereby protecting them from negation and criticism.

Fourth, evidentials function as engagement markers. Engagement markers are the devices that the writer explicitly addresses the reader, either to focus their attention or include them as discourse participants. In addition to creating an impression of authority, integrity and credibility through the choice of hedges, boosters, self-mention and attitude, the writer is able to either highlight or downplay the presence of the reader in the text. In any communicative situation, an orientation to the reader is crucial in securing social and rhetorical objectives. Self-mention provides a way for the writer to intrude into the discourse to stamp his personal authority onto his argument or step back from the discourse and disguise his involvement. In other words, these evidentials refer to writer-oriented features for they provide the writer with the devices to present himself. Engagement markers are the other side of the coin. They are more reader-oriented. Academic writers do more than simply push themselves and their ideas forward. They also have to recognize the presence of their readers, pulling them along with their argument, focusing their attention, recognizing their uncertainties, including them as discourse participants and guiding them to interpretations. Some types of evidentials also show engagement features, as illustrated in the following.

Engagement features can be shown in the cases where the information source is the inclusive pronoun we. Consider the following examples.

(21) In the excerpt in Fig. 2, we can see examples that the teacers successfully drew on several specific aspects of her English competence to achieve her teaching aims.

(22) When we focus specifically on their organizational role, we can see that these labels also mark the writer's stance.

By using inclusive we in Examples (21) and (22), the writers include the reader as the discourse participant. It can be seen that the inclusive pronoun we invites the reader into the argument and presupposes a set of mutual understandings which serve to identify the writer and the reader of the same discipline. This strategy, on the one hand, involves the reader in the discourse-making process so that they are more likely to believe what they experience by themselves, as illustrated in the examples above. On the other hand, this strategy can appeal to the solidarity between the writer and the reader and mitigate the individual assertive and imposeness.

\section{CONCLUSION}

Our corpus-based study has shown that in RAs evidentiality function as metadiscourse devices. These devices play a very important role in the construction and attainment of persuasion. The specific findings are presented as follows:

First, different evidential types and their respective linguistic realization forms function as different metadiscourse devices and therefore perform different functions.

Secondly, in the category of interactive metafunction, other-reporting evidential can serve as Evidential in Hyland's model, which helps the writer to establish the intertextual links. However, the self-reporting evidentials mainly serve as the Endophoric markers to make the information more salient, to guide the reader's thinking direction and at the same time to make the claims interpreted in the way the writer prefers to.

Thirdly, in the category of interactional metadiscourse, to make his claims more conservertive, tentative so as to promote his credibility, modesty and humility, the writer tends to resort to inferring evidential denoting low degree of certainty, some self-reporting verbs (e.g. suggest) and belief evidential. At the same time, to Make the claims more assertive and authoritative so as to establish his credibility and authority, the writer has the choice among Inferring 
evidential denoting high degree of certainty, some self-reporting verbs(e.g. suggest), the choice of information source. Besides, the use of Self-reporting evidential and Belief evidential help to Show the writer's individuality, and authority and the use of Sensory evidential and Evidentials denoting common knowledge can invite the readers to the discourse process and appeal to the solidarity between the writer and the reader.

In sum, functioning as metadiscourse devices is an important interpersonal function of evidentiality in RAs, and contributes much to creating a reader-friendly, more coherent and more convincing text.

Our evidential study from metadiscourse perspective is an attempt to examine the functions of evidential besides indicating the information source of a proposition. It lays a foundation for the future research and provide orientations for further study. First, the functions of evidentiality can be further studied from other perspectives such as cognitive linguistics, pragmatics, critical discourse analysis, positive discourse analysis, sociolinguistics and so on; Second, because of the genre convention, evidential use in other genres, even evidential use across genres is worthy of more research; Third, evidential use across languages is believed to be an interesting topic in furture evidential study.

\section{ACKNOWLEDGEMENT}

This work is supported by Chinese Educational Bureau [grant number: 11YJC740128], Chinese National Social Science Grant [grant number: 13CYY087], and Program for the Outstanding Innovative Teams of Higher Learning Institutions of Shanxi (OI T grant number: 2013052004). It is also Supported by Program for New Century Excellent Talents in University (NCET grant number: NCET-13-0884)

\section{REFERENCES}

[1] Aikhenvald, A. (2004). Evidentiality. Oxford: Oxford University.

[2] Aikhenvald, A. and R. Dixon.(2003).Studies in Evidentiality. Amsterdam/Philadelphia: John Benjamins Publishing Company.

[3] Boas, F. (1911). Handbook of American Indian Languages (Part 1). Washington: Government Printing Office.

[4] Boas, F. (1938). Language. In F. Boas (ed.). General Anthropology. Boston, New York: D.C. Heath and company.

[5] Bussmann, H. (1996). Routledge dictionary of language and linguistics. London: Routledge.

[6] Chafe, W. (1986). Evidentiality in English conversation and academic writing. In W. Chafe and J. Nichols (eds.). Evidentiality: The linguistic coding of epistemology. Norwood, NJ: Ablex.

[7] Chafe, W. and J, Nichols. (eds.) (1986). Evidentiality: The Linguistic Coding of Epistemology. Norwood, NJ: Ablex.

[8] Crismore, A. (1983). Metadiscourse: What is it and How is it Used in school and Non-school Social Science Texts. Urbana-Champaign: University of Illinois.

[9] Fairclough, N. (1992)..Discourse and Social Change. Cambridge: Polity Press.

[10] Fang, H. M. (2006). Review of Evidential studies. Journal of Contemporary Foreign Languages, 28, 191-196.

[11] Fang, H. M. (2005). A Systemic-functional Approach to Evidentiality. Unpublished doctoral dissertation, Fudan University, Shanghai.

[12] Halliday, M. A. K. and C. M. I. Matthiessen. (2004). An Introduction to Functional Grammar. London: Arnold.

[13] Hu, Z. L. (1994). Evidentiality in language. Foreign Languages Teaching and Research, 36, 9-15.

[14] Hu, Z. L. (1995). Evidentiality in Chinese and Discourse Analysis. Journal of Hubei University, 21, 13-23.

[15] Hyland, K. (1998). Persuasion and context: The pragmatics of academic metadiscourse. Journal of Pragmatics, 30, 437-455.

[16] Hyland, K. (2005). Metadiscourse. London: Continuum.

[17] Ivanic, R. and S, Weldon. (1998). Researching the writer-reader relationship. In Candlin, C. N. and K. Hyland (eds.). Writing: Texts, process and practices. London and New York: Longman.

[18] Lazard, G. (2001). On the grammaticalization of evidentiality. Journal of Pragmatics, 33, 358-68.

[19] Martin-Arrese, J. (2004). Perspectives on Evidentiality and Modality. Madrid: Editorial Complutense.

[20] Mushin, I. (2001). Evidentiality and Epistemological Stance: Narrative Retelling. Amsterstam/Philadelphia: John Benjamins Publishing Company.

[21] Mushin, I. (2000). Evidentiality and Deixis in Narrative Retelling. Journal of Pragmatics, 32: 927-957.

[22] Niu, B. Y. (2005). Review of Evidential Theory Aborad. Contemporary Linguistics, 43, 53-61.

[23] Palmer, F. (1990). Modality and the English Modals. London: Longman.

[24] Palmer, F. (1986/2001). Mood and Modality. Cambridge: Cambridge University Press.

[25] Tang, B. (2007). Systemic-functional Approach to Discourse Features of Evidentiality in English News Reports of Epidemic Situation Update. Unpublished doctoral dissertation, Fudan University, Shanghai.

[26] Thomas, S. and Hawes, T. P. (1994). Reporting verbs in medical journal articles. Englsih for Specific Purposes, 2, $134-55$.

[27] Vande Kopple, W. (1985). Some exploratory discourse on metadiscourse. College Composition and Communication, 36, 82-93.

[28] White, P. R. R. (2003). Beyond modality and hedging: a dialogic view of the language of the intersubjective stance. Text-Special Edition on Appraisal, 3, 259-84.

[29] Williams, J. (1981). Style: Ten Lessons in Clarity and Grace. Boston: Scott Foresman.

[30] Yang, L.X. (2009). Evidentiality in English Research Articles. Unpublished doctoral dissertation, Xiamen University, Xiamen.

[31] Yang, L.X. (2010) Genre Perspective on Evidentiality. Proceedings of $36^{\text {th }}$ ISF. Macquarie University Press.

[32] Zhu, Y. S. (2006). On Evidentiality in Chinese. Journal of Contemporary Foreign Languages 29, 331-33. 
Linxiu Yang is currently an associate professor at the Foreign Languages School of Shanxi University, China. She obtained her $\mathrm{PhD}$ in July 2009 in Xiamen University. Her current research interests include functional linguistics and discourse analysis. She has published over 10 academic articles in the areas of discourse studies, functional linguistics and foreign language teaching and learning in Journal of Pragmatics and Discourse Studies. 